\title{
CSHP 2015: Something for Everyone
}

\author{
Neil J MacKinnon
}

$\mathrm{O}$ ne of the most tangible ways by which hospital pharmacists across Canada can work together to improve the medication-use system is CSHP 2015, a practice excellence initiative for pharmacists in hospitals and related health care settings (www.cshp.ca/programs/cshp2015/index_e.asp). The overall aim of CSHP 2015 is to enhance the effective, scientific, and safe use of medications and to contribute meaningfully to public health, thereby improving the health of Canadians. This aim will be accomplished by the achievement of 6 goals and 36 underlying measurable objectives. CSHP 2015 can help to move hospital pharmacy in Canada forward with one influential and cohesive force, putting pharmacists in a proactive position to affect patient care.

CSHP 2015 really does have something for everyone. "How so?", you might ask, and I'm glad you did. Allow me to show you.

If you are a clinical pharmacist, CSHP 2015 can help you to promote pharmacy excellence in your own practice setting. The first goal of CSHP 2015 is to increase the extent to which pharmacists help individual hospital inpatients achieve the best use of medications. Members of the Canadian Society of Hospital Pharmacists can take advantage of a tool kit focusing on the provision of complex inpatient care and the pharmacist's role in the provision of that care. The second tool kit ("From paper to practice: incorporating evidence into your pharmacy practice") contains support for fostering an evidence-based pharmacy practice, which targets achievement of the third goal.

If you are a pharmacist with drug distribution responsibilities, CSHP 2015 can help you to optimize the drug distribution system in your practice setting. Another of the goals of CSHP 2015 is to increase the extent to which pharmacy departments in hospitals and related health care settings have a significant role in improving the safety of medication use. A

forthcoming CSHP 2015 tool kit, "One dose at a time: Implementing a unit-dose medication management system", will provide practical advice and tips for improving the drug distribution system.

If you are a supervisor, manager, or director of a hospital pharmacy department, CSHP 2015 can be

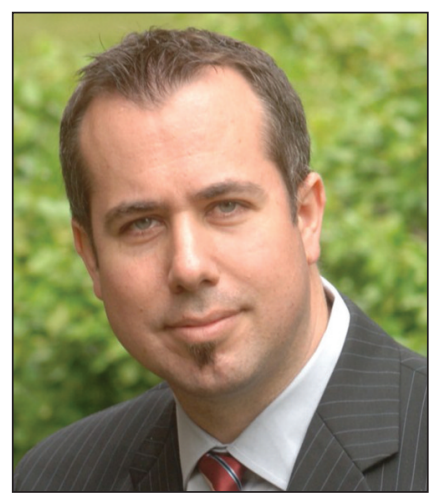
used to justify and support new pharmacy services or programs and can be part of your pharmacy department's strategic plan for patient care and pharmacy practice excellence. You can appreciate progress toward achieving the goals through a special CSHP 2015 section in the biennial Hospital Pharmacy in Canada Survey. In addition, the CSHP 2015 Crosswalk links each of the 36 objectives to other related initiatives (including Safer Healthcare Now! and Accreditation Canada) and provides the scientific evidence supporting each of the objectives. The biennial CSHP 2015 Facilities Survey explores both the priority ranking and degree of implementation of the goals and objectives.

Finally, if you are a patient, you can take comfort from knowing that CSHP 2015 will help to ensure that medication use in our nation's hospitals is effective, safe, and evidence-based.

Neil J MacKinnon, BSc(Pharm), MSc(Pharm), PhD, FCSHP, is Past President and Vision Liaison of the CSHP. 